\title{
Fixed-bed reactors with periodic flow reversal: experimental results for catalytic combustion
}

\author{
Ulrich Nieken ${ }^{1}$, Grigorios Kolios, Gerhart Eigenberger* \\ University of Stuttgart, D-70199 Stuttgart,Germany
}

\section{Introduction}

Adiabatic fixed-bed reactors with periodic flow reversal can be used to carry out reactions with a low overall exothermicity, autothermally. If the feed is at ambient temperature the periodic operation is used to establish a regenerative heat exchange between the effluent gas and the feed. This type of operation has been proposed and demonstrated by Matros et al. [1-4] and is now being applied industrially for $\mathrm{SO}_{2}$ oxidation and primarily for the catalytic combustion of traces of hydrocarbons in exhaust air [5]. Investigations on using periodic flow reversal for other reactions including methanol synthesis $[6,7]$, methane reforming [8] and styrene synthesis [9] have also become known.

In the following we will focus on the application of flow reversal for catalytic combustion using experimental results from a laboratory reactor set-up. The target of the studies is to demonstrate the influence of the main operational parameters and to provide guidelines for the design and operation of these reactors. An analysis based upon detailed mathematical modelling has been published elsewhere $[5,10,11]$.

The main advantage of a fixed-bed reactor with periodic flow reversal in catalytic combustion is its energy efficiency which exceeds that of autothermal reactors with recuperative heat exchange considerably. In conventional operation the effluent gas from an adiabatic fixed-bed is used to heat up the cold feed in an external heat exchanger in preferably countercurrent operation. Using standard heat exchanger technology an adiabatic temperature rise of the catalytic combustion of more than $100-150 \mathrm{~K}$ is necessary for autothermal operation. However, with a properly designed fixed-bed reactor with periodical flow reversal, a feed gas with an adiabatic temperature rise of $10 \mathrm{~K}$ can be treated.

Fig. 1 shows the basic mode of operation. After preheating the fixed-bed to reaction temperature, the cold gas enters the reactor. In a narrow heat-exchange zone the gas is heated up to ignition temperature and conversion takes place. Since the fixed bed is cooled by the cold feed, the temperature front will move slowly in the flow direction. After a certain

*Corresponding author.

'U. Nieken is now with BASF AG, Ludwigshafen. Germany. 


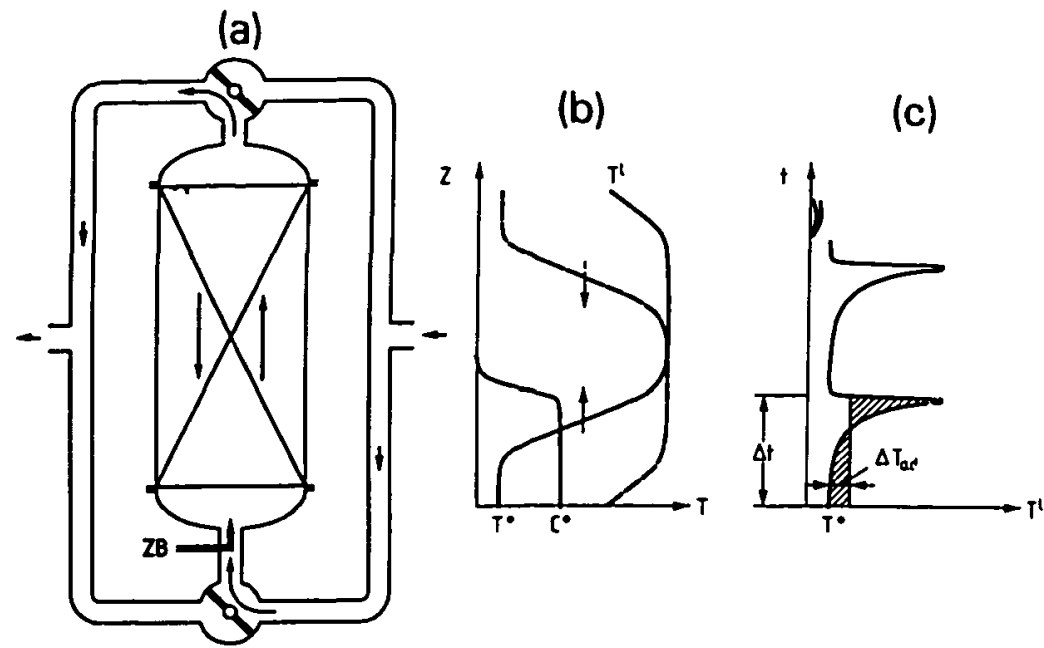

Fig. 1. Fixed-bed reactor with periodic flow reversal. (a) Reactor scheme, (b) temperature and concentration profiles in the oscillating steady state just before flow reversal, (c) outlet temperature vs. time.

section of the fixed bed has been cooled down, the flow direction is reversed and a new front moves into the bed from the opposite side, while the first front is pushed back. After a large number of flow reversals a steady state of periodic operation is established. The reaction front then moves back and forth in a completely symmetrical way and the temperature and concentration profiles at each half-period are mirror images of each other (Fig. lb). The total heat generated by reaction is released together with the effluent gas, leading to a saw tooth like exit temperature profile over time (Fig. 1c). Assuming adiabatic operation, the integral mean exit temperature exceeds the inlet temperature by the value of the adiabatic temperature rise. Obviously both end sections of the fixed bed serve as regenerative heat exchangers.

In practice special precautions must be taken to prevent unreacted gas in the entrance pipe and hood of the packed bed from being flushed into the exit line if the flow is reversed. This can either be done by using e.g. a three bed design with a separate purging step or rotating fixed beds with a purging segment [12].

\section{Experimental set-up}

The experimental set-up used is shown in Fig. 2. The reactor consists of a tube, $85 \mathrm{~cm}$ in length and $5 \mathrm{~cm}$ in diameter, into which pieces of ceramic monolith catalysts are positioned and sealed with a mineral fiber ribbon to prevent bypassing of gas at the tube wall. Two different monolith types for total oxidation of automobile exhaust gas provided by Degussa were used. They have square channels of $1 \mathrm{~mm}$ and $2 \mathrm{~mm}$ width, respectively, the active ingredient is Pt on alumina. 14 thermocouples are mounted at different axial and radial positions to monitor the temperature profile. The flow direction can be switched by four 

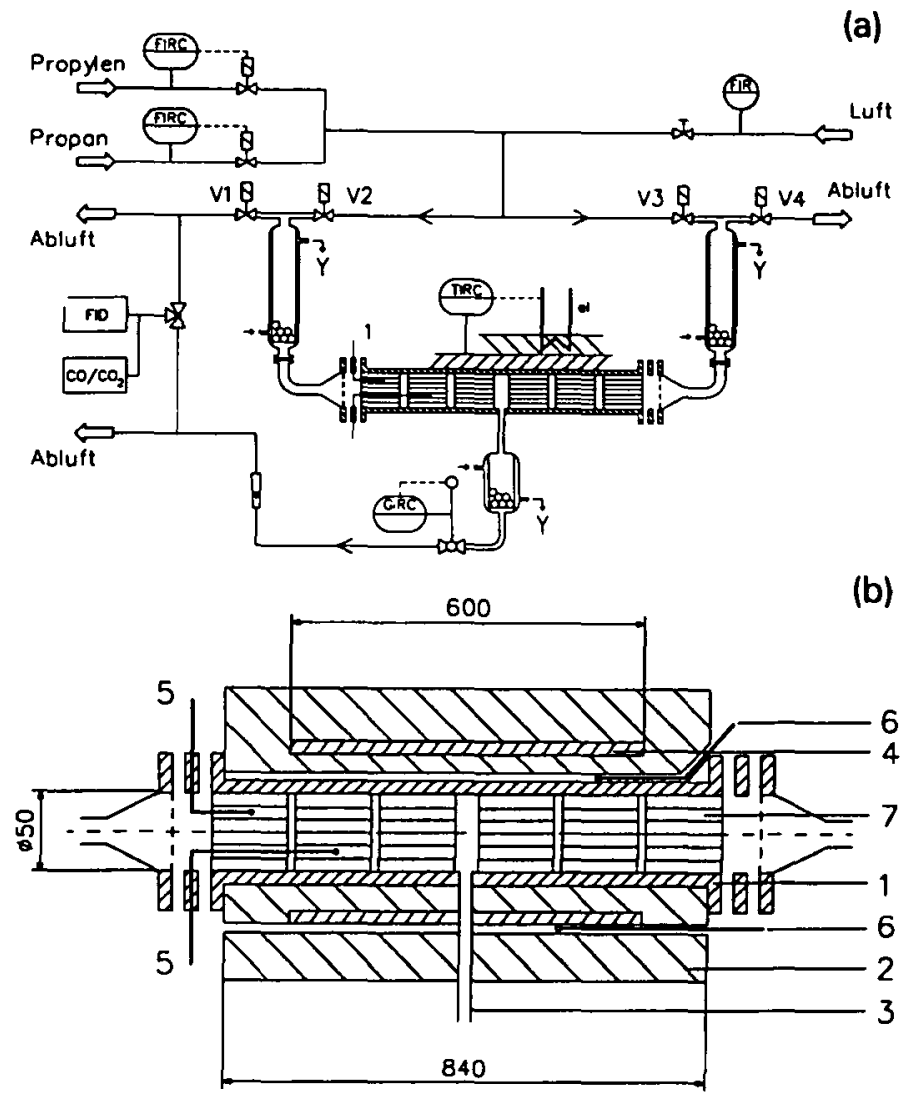

Fig. 2. Experimental set-up. (a) Flow sheet; (b) fixed-bed reactor: (1) reactor tube, (2) insulation, (3) side stream, (4) electrical compensatory heating, (5) thermocouples, (6) capillary with movable thermocouple, (7) sections of monolith catalyst.

magnetic valves in the feed and exit lines. Small amounts of propane and propylene in air are used as pollutants to study the influence of gases with different ignition temperatures on the operation of the reactor. From the middle of the reactor hot gas can be withdrawn with an adjustable flow-rate. Its concentration as well as the feed and effluent concentrations can be measured on-line by a flame ionisation detector (FID) for total content of hydrocarbons and by $\mathrm{CO}$ and $\mathrm{CO}_{2}$ infrared sensors.

It is well known that the most crucial point in the operation of a laboratory scale autothermal reactor is the limitation of heat losses to the surroundings. Therefore the reactor was insulated first with a $35-\mathrm{mm}$ layer of mineral fiber on which an electrical compensation heater was positioned along the central part of the reactor $(600 \mathrm{~mm})$. A second layer of 60 $\mathrm{mm}$ insulating material was positioned on top which extended over the whole reactor tube length (Fig. 2b). In order to prevent overcompensation the temperature of the compensation heater was measured in the middle of the reactor and controlled to a value about $20 \mathrm{~K}$ below the value measured at the same axial position in the monolith. 

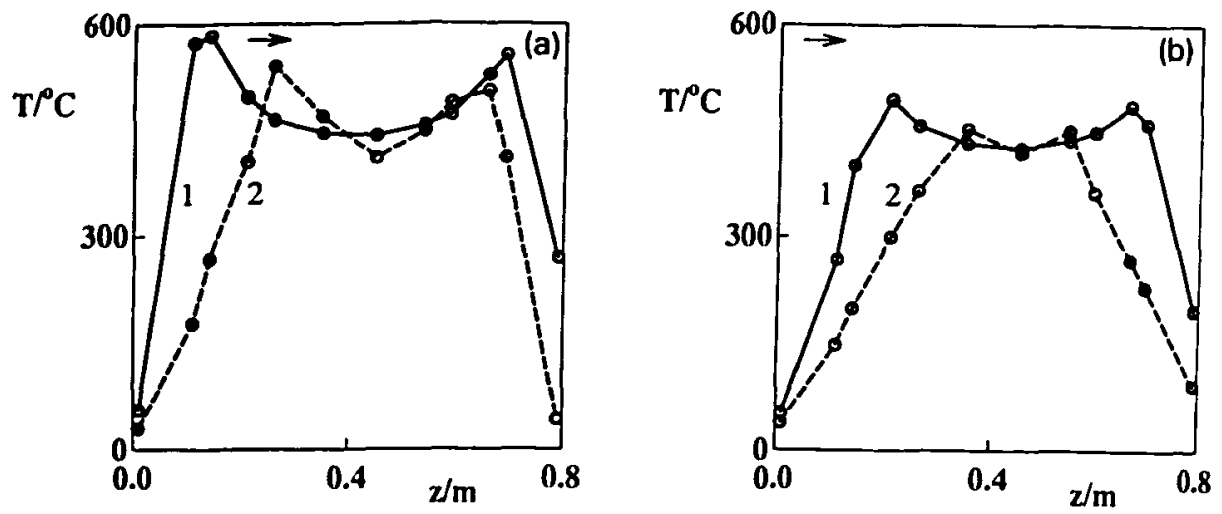

Fig. 3. Steady-state temperature profiles with (1) and without compensatory heating (2). (a) Propane oxidation, $\Delta T_{\infty \mathrm{c}}=120 \mathrm{~K}, q_{\mathrm{et}}=150 \mathrm{~W}$. (b) Propane oxidation, $\Delta T_{\infty \mathrm{d}}=70 \mathrm{~K}, q_{\mathrm{el}}=110 \mathrm{~W}$.

Thus a reasonable, but not perfect compensation of heat losses was achieved. Fig. 3 shows the measured temperature profiles for different feed concentrations with and without compensatory heating. The dent in the middle of the temperature profiles is caused by heat losses and is more evident at higher maximum temperatures. Fig. 3 shows that the heat losses produce a decline in the slopes of the temperature profile but they have little effect on the maximum temperature. During the start-up the electrical compensation heater was used to heat up the catalyst to the necessary ignition temperature.

\section{Influence of operational parameters}

In the following the influence of operational parameters like switching frequency, feed concentration and feed composition will be discussed. For better comparison, the feed concentration is specified by the adiabatic temperature rise $\Delta T_{\mathrm{adj} j}$. The temperature rise caused by the hydrocarbon $j$ in the feed is given by

$$
\Delta T_{a \mathrm{~d}, j}=\frac{\left(-\Delta h_{\mathrm{r}}\right)_{j} g_{j}^{0}}{M_{j} C_{p \mathrm{G}}}
$$

where $\Delta h_{r}$ is the reaction enthalpy, $g_{j}^{0}$ the weight fraction in the feed, $M_{j}$ its molecular weight and $C_{p G}$ the total feed heat capacity. The profiles shown are taken just before flow reversal and the present flow direction is indicated by an arrow. Unless stated otherwise the operational parameters given in Table 1 were used in all subsequent experiments.

Table 1

Experimental operating conditions

\begin{tabular}{ll}
\hline Mass flow-rate & $G_{2}=1.09 \mathrm{~kg} /\left(\mathrm{m}^{2} \mathrm{~s}\right)$ \\
Feed temperature & $T^{0}=20^{\circ} \mathrm{C}$ \\
$\begin{array}{l}\text { Switching period } \\
\text { (time between feed switches) }\end{array}$ & $t=60 \mathrm{~s}$ \\
\hline
\end{tabular}




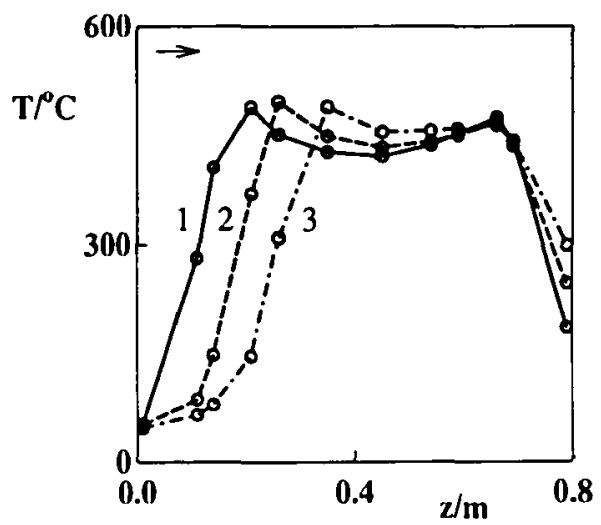

Fig. 4. Influence of the switching period (time between feed switches) $\Delta t$ for propane oxidation, $\Delta T_{\Delta}=70 \mathrm{~K}$. (1) $\Delta t=60 \mathrm{~s}$, (2) $\Delta t=120 \mathrm{~s}$, (3) $\Delta t=180 \mathrm{~s}$.

Fig. 4 shows the influence of the switching frequency. It is obvious that the front movement is directly proportional to the period length. An important result is that neither the slope nor the maximum of the temperature profile are effected by the switching frequency.

Fig. 5 shows the influence of the feed concentration for propane and propylene. For both hydrocarbons the maximum temperature increases with feed concentration, as expected. Surprisingly, the maximum temperature reaches much higher values in the case of propane oxidation than in the case of propylene oxidation in spite of the fact that the heat of reaction is the same in both cases. The reason is that propane has a lower reaction rate coefficient and a higher ignition temperature than propylene. As a consequence a greater part of the fixed bed is needed for regenerative heat exchange until sufficiently high temperatures are reached that allow for complete conversion.

Fixed-bed reactor operation with periodic flow reversal therefore exhibits an interesting self-stabilizing behavior: it automatically tends to adopt the temperature level which is necessary for total conversion. This feature has some interesting implications for catalyst
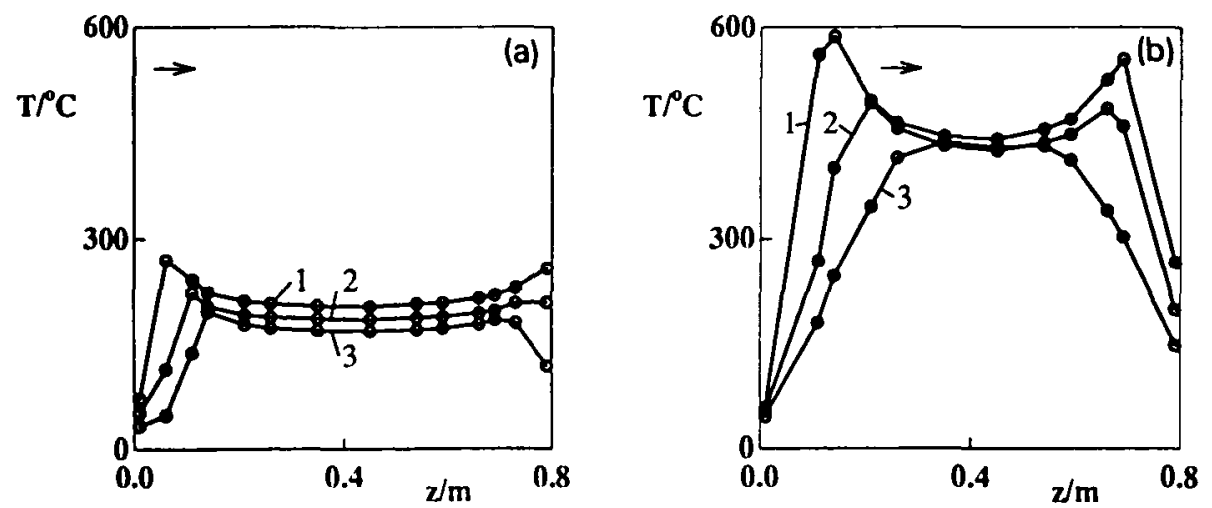

Fig. 5. Influence of the feed concentration, expressed as $\Delta T_{\infty \alpha}$ for propylene (a) and propane oxidation (b). (1) $\Delta T_{\nu \mathrm{d}}=120 \mathrm{~K}$, (2) $\Delta T_{\omega \omega}=70 \mathrm{~K}$, (3) $\Delta T_{\infty \mathrm{c}}=30 \mathrm{~K}$. 

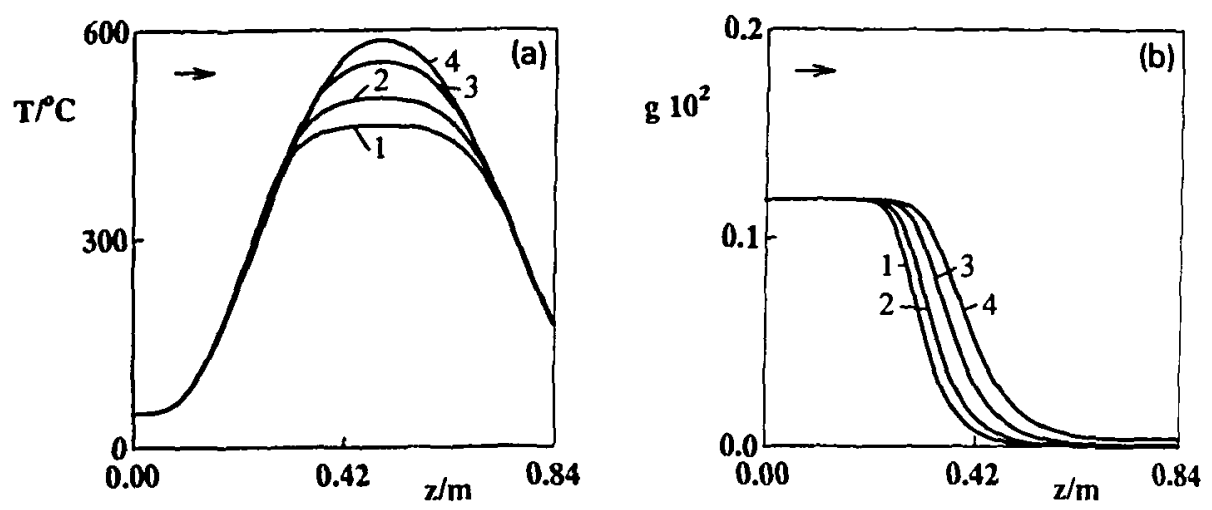

Fig. 6. Influence of relative catalyst activity $a$ on temperature (left) and concentration profiles (right). (1) $a=1$, (2) $a=1 / 2$, (3) $a=1 / 5$, (4) $a=1 / 10$. Simulation results for propane oxidation, $\Delta T_{m}=50 \mathrm{~K}, d_{\mathrm{n}}=2 \mathrm{~mm}$. ( $a$ is the ratio of the catalyst activity compared to the activity of the fresh catalyst).

deactivation. Fig. 6 shows calculated temperature and concentration profiles for the propane oxidation where the influence of decreasing catalyst activity has been simulated. The results show that total conversion can be retained until the activity has dropped to almost one tenth of the initial value. If the activity decreases further, an extinction of the reaction will take place. The extinction is caused by the fact that the portion of the catalyst bed with a sufficiently high temperature for the reaction is now too small to achieve total conversion.

It should be mentioned that the self stabilizing effect may lead into a vicious circle if a catalyst which is sensitive to temperature-induced deactivation is used. Deactivation will cause an increasing maximum temperature which in turn accelerates the deactivation. Thermally sensitive catalysts should therefore never be used in fixed-bed reactors with periodic flow reversal.

Changes in feed concentration and in feed composition are the most common disturbances in industrial air purification applications. If a mixture of feed components with different reactivities has to be treated, the facts discussed above may lead to multiple ignited steady states where either all or only part of the components are oxidized under the same operating conditions. This can be seen in Fig. 7 where steady-state temperature profiles $(1,2)$ are shown for a mixture of propane and propylene with feed concentrations corresponding to $\Delta T_{w \mathrm{~s}}=70 \mathrm{~K}$ for each component. Additionally temperature profiles for pure propane (3) or propylene (4) feed of $\Delta T_{\mathrm{ad}}=70 \mathrm{~K}$ are shown as well. In the 'upper steady state' (profile 1 in Fig. 7) both components are totally converted. The temperature profile is close to profile 3 where only propane is present in the feed. In the partially ignited steady state (profile 2) only propylene is oxidized and propane leaves the reactor unreacted; the temperature profile almost coincides with profile 4 where only propylene is present in the feed.

In order to totally convert the most inert component a sufficiently high-temperature level has to be sustained. Otherwise a situation as shown in Fig. 8 may result. Here the feed composition was switched from a propane concentration corresponding to $\Delta T_{\text {ad }}=70 \mathrm{~K}$ propane, to a propane-propylene mixture. In this mixture the propane concentration corresponds to $\Delta T_{\text {ad }}=12 \mathrm{~K}$ and the propylene concentration to $\Delta T_{\text {ad }}=58 \mathrm{~K}$. Again, the total adiabatic temperature rise is $70 \mathrm{~K}$. However, due to the low propane concentration the heat 


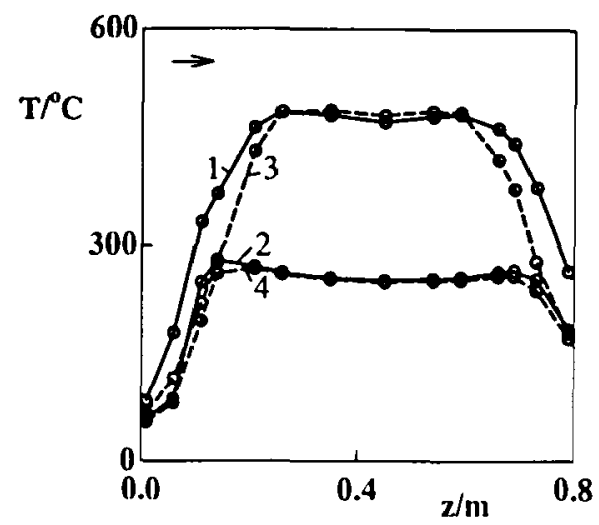

Fig. 7. Multiple steady states for a co-feed of propane $\left(\Delta T_{w 0}=70 \mathrm{~K}\right)$ and propylene $\left(\Delta T_{\infty}=70 \mathrm{~K}\right)$. (1,2) Multiple ignited steady states, (3) only propane in feed $\left(\Delta T_{\infty}=70 \mathrm{~K}\right),(4)$ only propylene in feed $\left(\Delta T_{\alpha u}=70 \mathrm{~K}\right)$.
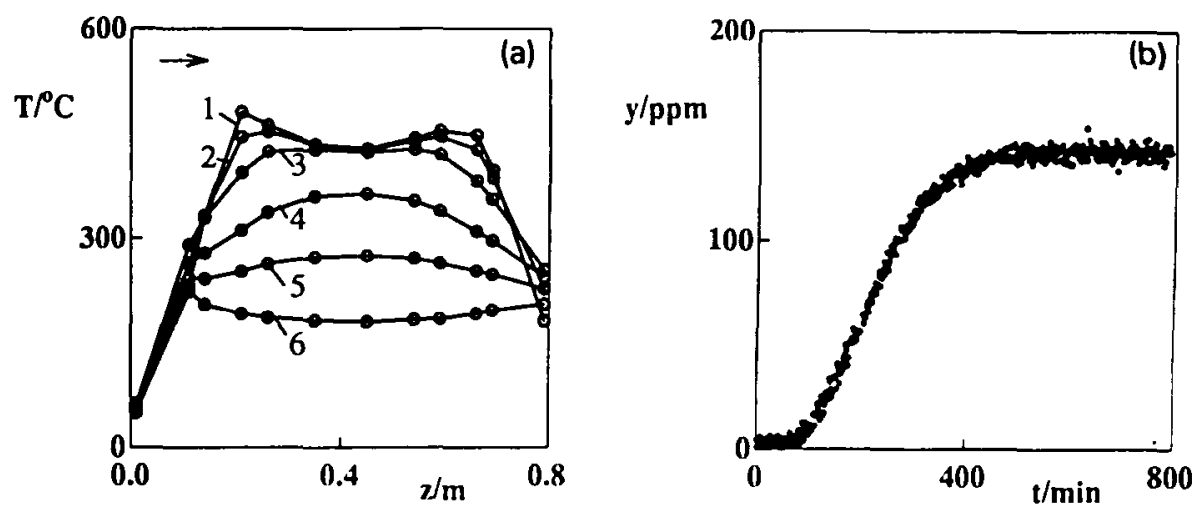

Fig. 8. Partial extinction after a step change in feed composition from $70 \mathrm{~K}$ propane, no propylene to $12 \mathrm{~K}$ propane, $58 \mathrm{~K}$ propylene. (a) Temperature profiles at time $t$ after the feed change: (1) $t=0,(2) t=7 \mathrm{~min}$, (3) $t=17 \mathrm{~min}$, (4) $t=170 \mathrm{~min}$, (5) $t=370 \mathrm{~min}$. (b) Propane exit concentration over time.

set free by the propane oxidation is too small to retain the necessary maximum temperatures of about $450^{\circ} \mathrm{C}$. The maximum temperature therefore drops to that of the partially ignited state $\left(T_{\max } \approx 200^{\circ} \mathrm{C}\right)$ where only propylene is oxidized. As indicated by the propane exit concentration (Fig. 8b), the extinction of the upper steady state is a slow process that takes several hours. After the partially ignited steady state is established a switch back to a pure propane feed of $\Delta T_{\text {ad }}=70 \mathrm{~K}$ will result in a total extinction since propane cannot be oxidized at $200^{\circ} \mathrm{C}$ to any reasonable extent.

\section{Approximate design of steady-state temperature profiles}

The experimentally observed behavior can be reproduced by detailed mathematical modelling as shown in $[11,13]$. Interestingly, the main features of the steady-state temperature 


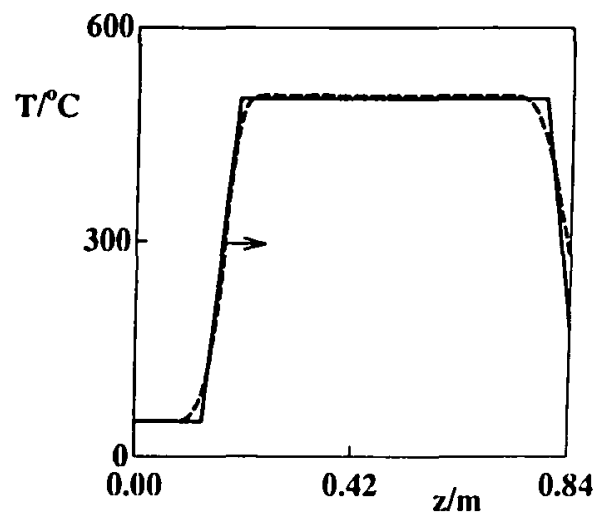

Fig. 9. Comparison between approximated (solid line) and detailed simulation (broken line) of the steady-state temperature profiles for propane oxidation.

profiles can be obtained by a rather simple procedure, which shows the influence of important design and operational parameters on the temperature profile in an explicit way. This procedure will be discussed briefly. Details can be found in $[5,11,13]$.

As Fig. 9 shows, the temperature profile can be described by the axial position and the slope of the temperature fronts and by the maximum temperature. The axial displacement of the reaction front can be calculated approximately with the moving front velocity $\omega$ which is given by the following equation

$$
\omega=\frac{G_{z} C_{p \mathrm{G}}}{(1-\varepsilon)\left(\varrho C_{p}\right)_{2}}\left(1-\frac{\Delta T_{\mathrm{ad}}}{T_{\max }-T^{0}}\right)
$$

Eq. 2 has first been derived by Wicke and Vortmeyer [14]. $G_{z}$ is the cross sectional mass flow velocity $\left[\mathrm{kg} /\left(\mathrm{m}^{2} \mathrm{~s}\right)\right], C_{p s}$ is the heat capacity of the catalyst bed, $\varepsilon$ its void fraction and $T^{\mathbf{0}}$ the feed temperature.

The slope of the temperature front can be calculated from

$$
\frac{\mathrm{d} T}{\mathrm{~d} z}=\frac{G_{z} C_{\mathrm{pG}}}{2 \lambda_{\mathrm{eff}}}
$$

where $\lambda_{\text {eff }}$ is the effective axial conductivity in a quasihomogeneous fixed bed reactor model. Using the equivalence relation between quasihomogeneous and two-phase models derived by Vortmeyer and Schäfer [15]

$$
\lambda_{\text {eff }}=\lambda_{s}(1-\varepsilon)+\frac{\left(G_{z} C_{p G}\right)^{2}}{\alpha a_{v}}
$$

$\lambda_{\text {ef }}$ can be specified in terms of the heat conductivity of the solid monolith matrix, $\lambda_{3}$, the specific outer surface area $a_{v}\left[\mathrm{~m}^{2} / \mathrm{m}^{3}\right]$ and the heat transfer coefficient $\alpha\left[\mathrm{W} /\left(\mathrm{m}^{2} \mathrm{~K}\right)\right]$ from the fluid to the catalyst surface. The only remaining unknown, $T_{\max }$, can in case of a single reaction be approximated with sufficient accuracy from the following integral equation 


$$
\frac{\Delta T_{\mathrm{ad}} G_{z}^{2} C_{p \mathrm{G}}}{2 \lambda_{\mathrm{eff}}}=\int_{T^{0}+\Delta T_{\mathrm{wd}} / 2}^{T_{\mathrm{max}}} a_{\mathrm{v}} B(T) \mathrm{d} T
$$

where $B(T)$ is the rate of mass transfer related to the surface area. For a first order reaction with external mass transfer limitation $B(T)$ is given by

$$
B(T)=\frac{M_{\mathrm{L}} p}{R T} \frac{k(T) \beta}{k(T)+\beta} ; k(T)=k_{\times} \mathrm{e}^{-E / R T}
$$

$\beta$ is the external mass transfer coefficient at the catalyst surface, $k(T)$ is the rate constant related to the catalyst surface area and $M_{\mathrm{L}}$ the mean molecular weight.

With the equations shown above it is possible to get a reasonable picture of the influence of the operational and design parameters on the steady-state temperature profile. Fig. 9 shows the degree of accuracy reached. The solid temperature profile is constructed with the slope, the axial displacement of the temperature front and the maximum temperature using the above equations. The result of the detailed two-phase model simulation is shown as a broken line.

From Eq. 5 it can be seen that $T_{\max }$ increases if $\Delta T_{\text {ad }}$ increases. The influence of the mass flow velocity $G_{z}$ on $T_{\max }$ is somewhat more intricate. It has a direct influence on the left hand side of Eq. 5 and on $\lambda_{\text {eff }}$ (Eq. 4). All together $T_{\max }$ increases with increasing $G_{z}$ until a limiting value is reached at high flow-rate (Fig. 10).

The effective axial conductivity $\lambda_{\text {efr }}$ is the design parameter with the most pronounced influence on the maximum temperature. As can be seen from Eq. $4, \lambda_{\text {cff }}$ depends both on the axial conductivity of the solid, $\lambda_{\text {, }}$, and on the product $\left(\alpha a_{v}\right)$ of heat transfer coefficient and specific external surface area. An increase of $\lambda$, directly decreases $T_{\max }$. This feature will be used in the example of Fig. 16 to control the maximum temperature of the reactor. An increase of the width of the monolith channels also increases $\lambda_{\text {eff }}$ via $\left(\alpha a_{v}\right)$ (Eq. 4). The influence on the maximum temperature however is less pronounced since $\left(\alpha a_{\mathrm{v}}\right)$ in $\lambda_{\text {erf }}$ tends to be compensated by $\left(\beta a_{v}\right)$ in the integrand of Eq. 5 .

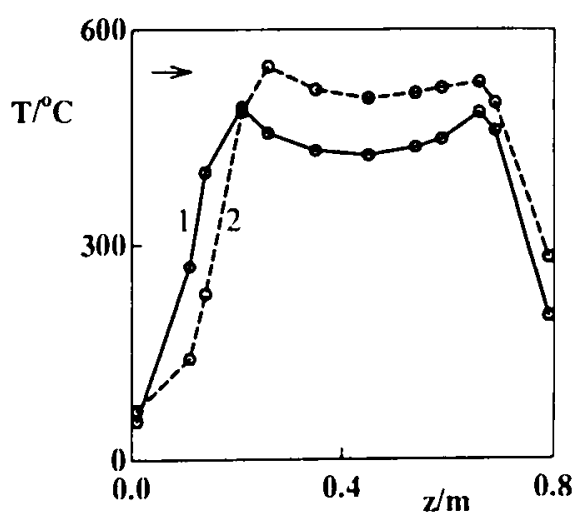

Fig. 10. Influence of the mass fiow velocity $G_{z}$ for propane oxidation. (1) $G_{z}=11 \mathrm{~kg} /\left(\mathrm{m}^{2} \mathrm{~s}\right)$, (2) $G_{z}=2.2 \mathrm{~kg} /$ $\left(\mathrm{m}^{2} \mathrm{~s}\right)$. 

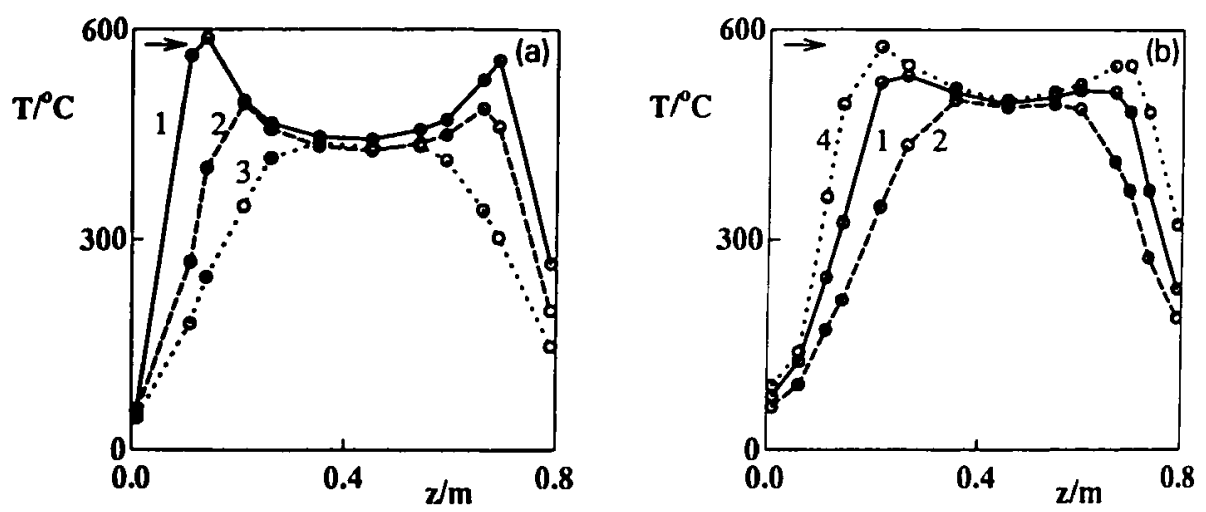

Fig. 11. Influence of the monolith channel diameter $d_{\mathrm{n}}$ for propane oxidation. (a) $d_{\mathrm{h}}=1 \mathrm{~mm}$, (b) $d_{\mathrm{n}}=2 \mathrm{~mm}$. (1) $\Delta T_{\infty \mathrm{d}}=120 \mathrm{~K}$, (2) $\Delta T_{\infty}=70 \mathrm{~K}$, (3) $\Delta T_{\infty}=30 \mathrm{~K}$, (4) $\Delta T_{\infty \mathrm{d}}=160 \mathrm{~K}$.

Fig. 11 shows experimental results with two different monoliths with a channel width of 1 and $2 \mathrm{~mm}$. In accord with Eq. 3 the slope of the temperature profile is smaller in the monolith with the larger channel width. This causes an earlier extinction of the $2 \mathrm{~mm}$ monolith since the maximum temperature 'shoulder' is narrower compared to the $1 \mathrm{~mm}$ monolith. The reactor equipped with the $2 \mathrm{~mm}$ monoliths turned out to extinguish if the feed concentration of propane was lowered to a value corresponding to $\Delta T_{\text {ad }}=50 \mathrm{~K}$ whereas the reactor equipped with the $1 \mathrm{~mm}$ monoliths could be run stable with $\Delta T_{\text {ad }}=30 \mathrm{~K}$.

\section{Inert sections}

Since the inert front and end sections serve primarily as regenerative heat exchangers it is tempting to replace them by inert material. Fig. 12 shows a comparison of propylene oxidation in a reactor without and with inert front and end sections. In the latter case the

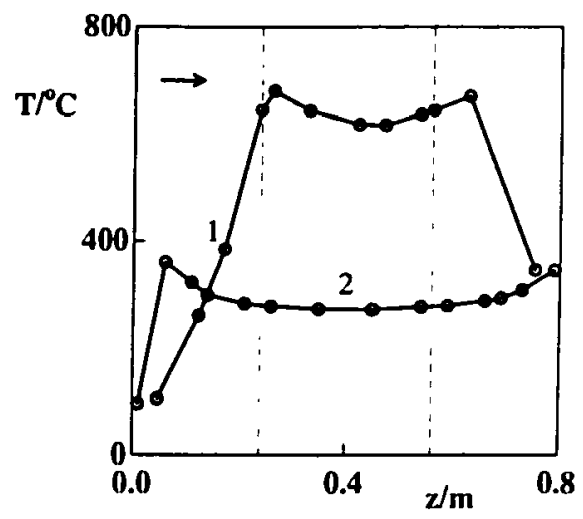

Fig. 12. Influence of inert front and end sections for propylene oxidation. (1) $\Delta T_{ \pm \alpha}=100 \mathrm{~K}, G_{z}=1.31 \mathrm{~kg} /\left(\mathrm{m}^{2}\right.$ s), two inert sections of $25 \mathrm{~cm}$ each. (2) $\Delta T_{\infty}=120 \mathrm{~K}, G_{z}=1.09 \mathrm{~kg} /\left(\mathrm{m}^{2} \mathrm{~s}\right)$, no inert sections. 

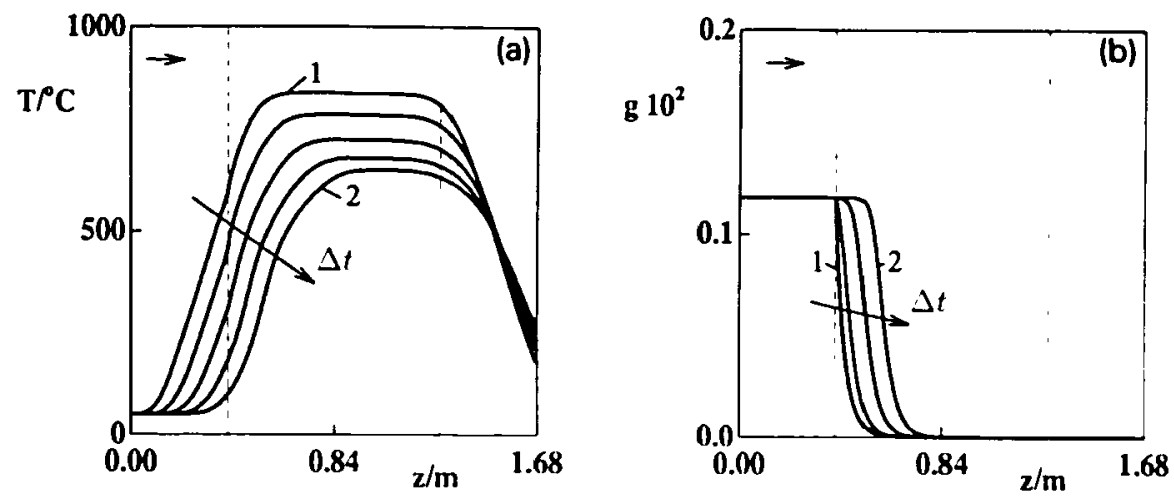

Fig. 13. Simulation results for the influence of the switching penod $\Delta t$ with inert front and end sections of $04 \mathrm{~m}$ each for propane oxidation in a monolith with $d_{\mathrm{h}}=2 \mathrm{~mm}$ for $\Delta t=60 \mathrm{~s}(1) ; \Delta t=90 \mathrm{~s}, 120 \mathrm{~s}, 150 \mathrm{~s}$ and $180 \mathrm{~s}$ (2). (a) Temperature profiles. (b) Mass fraction profiles.

maximum temperature is more than $400 \mathrm{~K}$ higher than in the first in spite of the fact that the adiabatic temperature rise is $20 \mathrm{~K}$ lower. This is a consequence of the fact that in the latter case the area of regenerative heat exchange exceeds substantially the area that establishes automatically if active catalyst is used over the whole reactor length. The introduction of inert front and end sections is therefore a simple method to increase the maximum temperature also for components with low catalytic ignition temperature and to prevent the occurrence of multiple ignited steady states as in Fig. 7. It should be mentioned however, that with inert front and end sections the maximum temperature does not stay constant if the length of the switching period is changed. As can be seen from the simulation results in Fig. 13, $T_{\max }$ decreases with increasing period length and approaches the value of the case without inert front and end sections if the switching period is sufficiently long.

\section{Hot gas withdrawal}

The heat released by reaction leaves the reactor with the exit gas while the exit temperature changes in a saw-tooth like fashion (Fig. lc). Due to the low mean exit temperature rise (equal to $\Delta T_{\text {ad }}$ ) this heat cannot be utilized. Instead it is much more efficient to use the heat of reaction at the highest temperature, $T_{\max }$. In ref. [16] different options for this goal have been proposed. However, in the case of catalytic combustion they are considerably less effective than hot gas withdrawal [11], which had first been proposed in [10]. Since the reaction is usually completed before the middle of the reactor (see e.g. concentration profiles in Fig. 13), the hot-side stream contains cleaned gas. As Fig. 14a shows, the result of hot gas withdrawal is a substantial contraction of the steady-state temperature profile into a steep profile with a very narrow shoulder. It should be noticed that the maximum temperature is hardly affected by the withdrawal of gas. This means that nearly all of the reaction heat can be recovered at $T_{\max }$. As a consequence, the exit temperature (at $z=0.84 \mathrm{~m}$ ) stays close to the inlet temperature. This is contrary to the case without hot gas withdrawal where the exit temperature rises to about $200^{\circ} \mathrm{C}$ at the end of the cycle (Fig. 14b). Hot gas withdrawal 

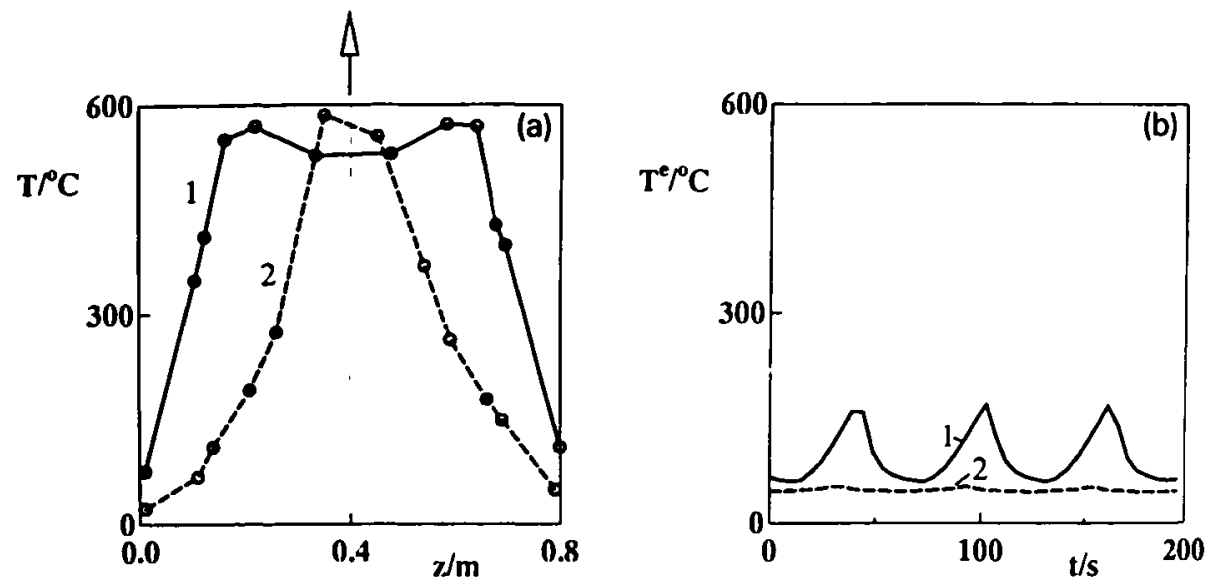

Fig. 14. Influence of the hot gas withdrawal for propane oxidation, $\Delta T_{a d}=120 \mathrm{~K}$, temperature profiles (a) and exit temperature over time (b). (1) No hot gas withdrawal, (2) $20 \%$ hot gas withdrawal.

has therefore two important benefits: the heat of reaction can be used at the highest temperature and the switching valves for the exit gas are not exposed to high-temperature peaks. Of course, the flow-rate of the hot-side stream must be limited to a value where less than the total reaction heat is withdrawn, otherwise the reactor will be extinguished. In the experiment shown in Fig. 14 the adiabatic temperature rise was $120 \mathrm{~K}$ and a maximum temperature rise of about $580 \mathrm{~K}$ was established. A simple overall energy balance reveals that a maximum of $120 / 580=21 \%$ of the gas flow can be withdrawn with the maximum temperature. Fig. 15 shows results of an experiment where this limit was violated intentionally. At first the temperature profile concentrates at the center of the tube while the

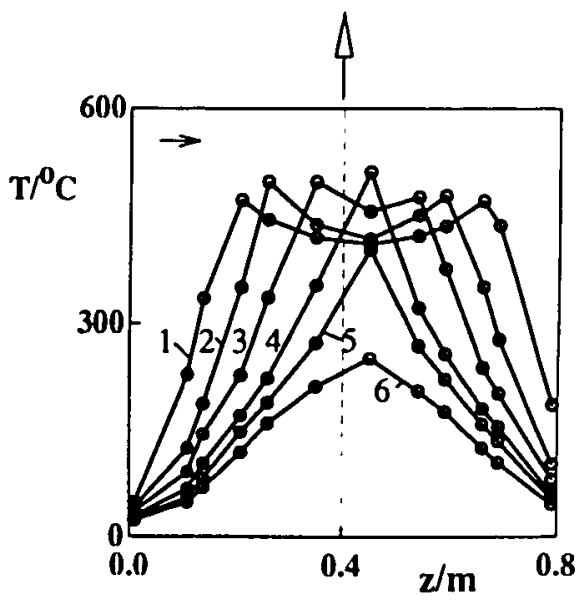

Fig. 15. Extinction of the reactor if too much hot gas is withdrawn (propane oxidation, $\Delta T_{\infty \mathrm{d}}=70 \mathrm{~K}$ with $25 \%$ hot gas withdrawal). Temperature profiles at time $t$ after start of withdrawal. (1) $t=0,(2) t=8 \mathrm{~min}$, (3) $t=26 \mathrm{~min}$, (4) $t=70 \mathrm{~min}$, (5) $t=135 \mathrm{~min}$, (6) $t=184 \mathrm{~min}$. 
additional heat, higher than the amount set free by the reaction, is taken from the heat stored in the packing. This process takes place for more than an hour (profile 4) before the maximum temperature decreases below its original value and the reaction becomes extinct.

\section{Control of the ignited state}

Like any autothermal reactor a fixed-bed reactor with periodic flow reversal has to be operated in the ignited steady state. That means that control actions should be taken in order to prevent extinction in case the feed is too lean or to limit excess temperatures in case the feed is too rich. In addition, in case of catalytic total oxidation of several components with differing ignition temperatures, a partially ignited state as shown in Figs. 7 and 8 must also be avoided.

Automatic control of our laboratory reactor with the above objectives has been discussed elsewhere $[11,13]$. In the following we point out possible provisions to control the reaction.

Extinction can always easily be prevented by adding combustible components in order to increase $\Delta T_{\text {ad }}$ of the feed.

In contrast, it is generally much more difficult to limit the maximum temperature in the case where the feed is too rich. The only way to decrease the maximum temperature for given operating conditions is to increase the effective axial conductivity $\lambda_{\text {eff }}$ (see Eq. 4). But an increase of $\lambda_{\text {efr }}$ also decreases the slopes of the temperature profile (see Eq. 3 ) towards a less stable profile with narrow shoulders. This means that the reactor will extinguish earlier if the feed concentration is decreased. Therefore the following control method

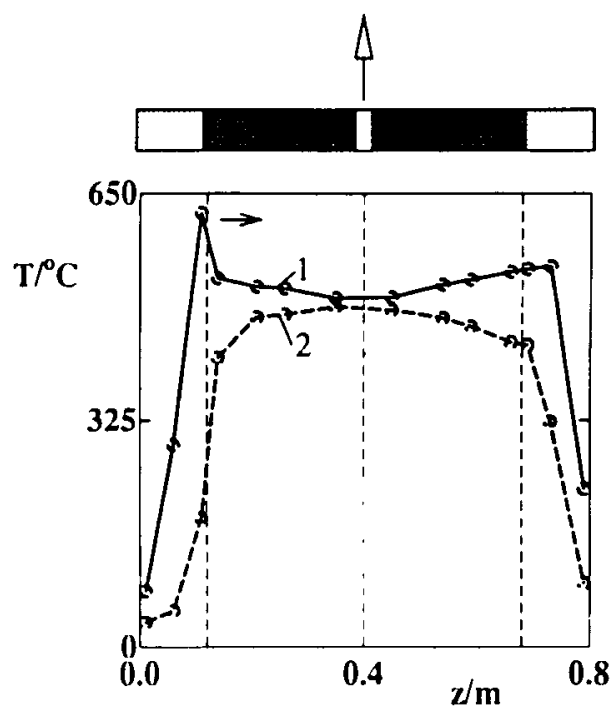

Fig. 16. Infivence of hot gas withdrawal in a structured packed bed with inert zones of low and an active zone of high axial conductivity for propane oxidation with $\Delta T_{\star \Delta}=100 \mathrm{~K}$. (1) No hot gas withdrawal, (2) with hor gas withdrawal. 
was conceived. The fixed bed is composed of two inert sections with low values of $\lambda_{\text {eff }}$ and an active part with high $\lambda_{\text {eff }}$. During times where the feed is rich, hot gas withdrawal can be executed which moves the temperature fronts into the active portion of the bed with high axial conductivity, so that the maximum temperature is reduced. During times where the feed is lean, no hot gas withdrawal takes place and the switching periods are kept short so that optimal heat recovery in the inert sections with low $\lambda_{\text {eff }}$ takes place.

Fig. 16 shows steady-state profiles with and without hot gas withdrawal if the catalyst in our reactor is structured in the above way. Through the hot gas withdrawal the peak temperature can be reduced by $120^{\circ} \mathrm{C}$. To increase $\lambda_{\text {eff }}$ in the active section of Fig. $16, \mathrm{Ni}$ plated copper wires of $0.8 \mathrm{~mm}$ diameter were positioned in every second monolith channel.

The third point has already been mentioned in connection with Fig. 13. If a sufficiently long inert front and end sections are used, the maximum temperature can be changed through the switching frequency. As long as only components with a low ignition temperature are present in the feed, a short period length will be chosen. This prevents the maximum temperature from dropping below the ignition temperature of components with a higher ignition temperature. If these components are present in sufficient concentrations, longer switching periods can be used in order to avoid an excessive increase of the peak temperature.

\section{Conclusions}

The influence of design and operating parameters on the behavior of a fixed-bed reactor with periodic flow reversal has been studied in a laboratory set-up for the case of catalytic total oxidation. The results are in accordance with detailed model simulations published elsewhere $[5,11,13,17]$. They show that the periodic operation is completely dominated by the regenerative heat exchange and that steady-state kinetics can be used.

Like any other autothermal reactor, a fixed-bed reactor with periodic flow reversal has to be operated in the ignited steady state. It was shown that totally and partially ignited steady states may exist under the same operating conditions if several combustible components with different ignition temperature are present in the feed.

Hot gas withdrawal from the middle of the packed bed proved to be a suitable method to utilize almost all of the heat of reaction at the highest temperature in the reactor and to prevent high temperature peaks at the respective exit valves. Together with an appropriate design of the fixed bed, composed of inert front and end sections with low effective axial conductivity and an active portion with large axial conductivity, hot gas withdrawal allows for an efficient control of the reactor under the conditions of both high and low feed concentrations.

\section{Notation}

$\begin{array}{ll}B, \mathrm{~kg} /\left(\mathrm{m}^{2} \mathrm{~s}\right) & \text { mass transfer rate per unit outer surface of the catalyst } \\ a_{\mathrm{v}}, \mathrm{m}^{2} / \mathrm{m}^{3} & \text { specific surface area } \\ c, \mathrm{kmol} / \mathrm{m}^{3} & \text { concentration } \\ C_{p}, \mathrm{~kJ} /(\mathrm{kg} \mathrm{K}) & \text { heat capacity }\end{array}$




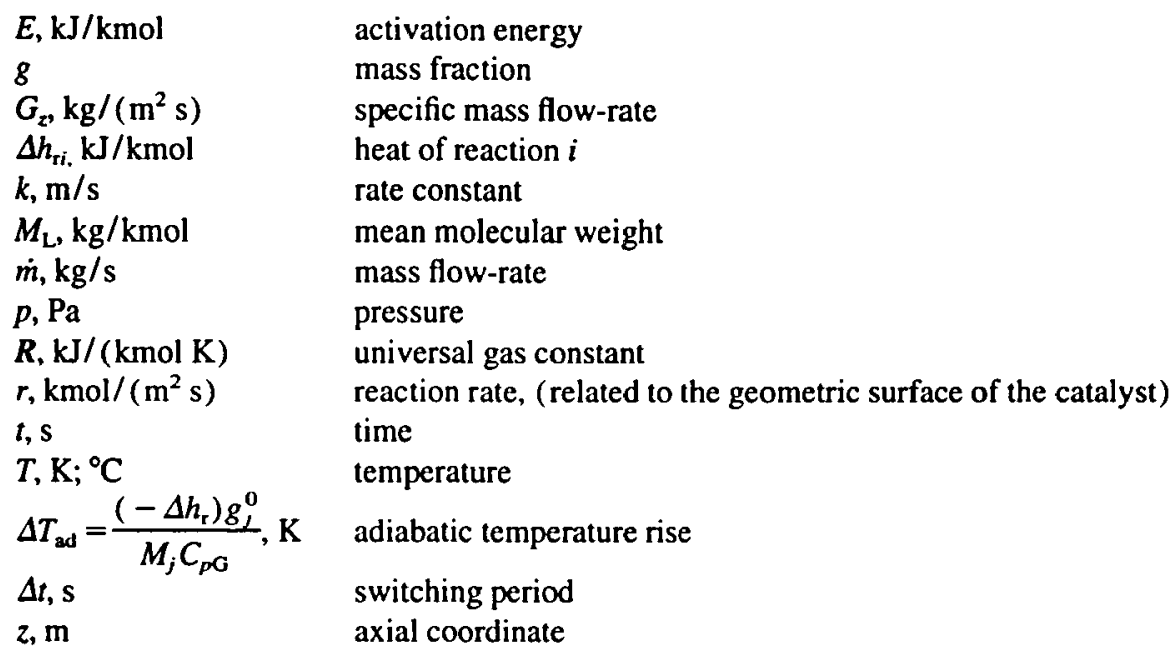

\section{Greek letters}

$\begin{array}{ll}\alpha, \mathrm{W} /\left(\mathrm{m}^{2} \mathrm{~K}\right) & \text { heat transfer coefficient } \\ \beta, \mathrm{m} / \mathrm{s} & \text { mass transfer coefficient } \\ \varepsilon & \text { void fraction } \\ \lambda, \mathrm{W} /(\mathrm{m} \mathrm{K}) & \text { heat conductivity } \\ \varrho, \mathrm{kg} / \mathrm{m}^{3} & \text { density } \\ \omega, \mathrm{m} / \mathrm{s} & \text { velocity of travelling reaction front }\end{array}$

\section{Lower indices}

$\begin{array}{ll}\text { eff } & \text { effective } \\ \mathrm{g} & \text { gas phase } \\ i & \text { reaction index }(i=1 \ldots I) \\ j & \text { component index }(j=1 \ldots J) \\ \mathrm{L} & \text { air } \\ \mathrm{s} & \text { solid }\end{array}$

Upper indices

0

feed

\section{References}

[1] G.K. Boreskov and Y.S. Matros, Catal. Rev. Scı Eng., 25 (4) (1983) 551-590.

[2] Y.S. Matros, Sulphur, 183 (1986) 23-29.

[3] Y.S. Matros, Chem. Eng Sc1.. 45 (8) (1990) 2097-2102. 
[4] Y.S. Matros, A.S. Noskov and V.A. Chumachenko, Chem. Eng. Process., 32 (1993) 89-98.

[5] G. Eigenberger and U. Nieken, Chem. Ing. Tech., 63 (8) (1991) 781-791. English version to be published in Int. J. Chem. Eng., 34(1) (1994) 4-16.

[6] K.M. Van den Busche, S.G. Neophytides, I.A. Zolotarskii and G.F. Froment. Chem. Eng. Sci., 48 (19) (1993) 3335-3345.

[7] S.G. Neophytides and G.F. Froment, Ind. Eng. Chem. Res., (31) (1992) 1583-1589.

[8] R.F. Blanks, T.S. Wittrig and D.A. Peterson, Chem. Eng. Sci., 45 (1990) 2407-2413.

[9] T.N. Haynes, C. Georgakis and H.S. Caram, Chem. Eng. Sci., 47 (1992) 2927-2932.

[10। G. Eigenberger and U. Nieken, Chem. Eng. Sci., 42 (1988) 2109-2115.

[11] U. Nieken. Ph.D. Thesis, Universität Stuttgart, 1993.

[12] G. Eigenberger, Fixed-Bed Reactors, Vol. B4 of Ullmann's Encyclopedia of Industrial Chemistry, VCH Verlagsgesellschaft. Weinheim, 1992, pp. 199-238.

[13] U. Nieken, G. Kolios and G. Eigenberger, to be published.

[14] E. Wicke and D. Vortmeyer, Zündzonen heterogener Reaktionen in gasdurchströmten Körnerschichten. Bericht Bunsengesellschaft, 63 (1959) 145-152.

[15] D. Vortmeyer and R.J. Schäfer, Chem. Eng. Sci., 29 (1974) 485-491.

[16] Y.S. Matros, Catalytic Processes under Unsteady-State Conditions, (Studies in Surface Science and Catalysis, Vol. 43), Elsevier, Amsterdam, 1989.

[17] U. Nieken, G. Kolios and G. Eigenberger, Regelung eines instationär betreibenen Reaktors mit FuzzyKontrollregeln, Jahrbuch 1993 Verfahrenstechnik und Chemieingenieurwesen, 1993, pp. 44-63. 